\title{
Endoscopic clipping of the Z-line (CMZL) helps recognize anatomical failures after Nissen fundoplication: technical report of a new method
}

\author{
Leonid Barkhatov ${ }^{1,2}$, Airazat M. Kazaryan ${ }^{1,3}$, Steinar Aasen ${ }^{4}$, Bjørn Edwin ${ }^{1,2,5}$ \\ ${ }^{1}$ The Intervention Centre, Oslo University Hospital - Rikshospitalet, Oslo, Norway \\ ${ }^{2}$ Institute of Clinical Medicine, Medical Faculty, University of Oslo, Oslo, Norway \\ ${ }^{3}$ Surgical Department, Finnmark Hospital, Kirkenes, Norway \\ ${ }^{4}$ Radiology Department, Oslo University Hospital - Rikshospitalet, Oslo, Norway \\ ${ }^{5}$ Department of HPB Surgery, Oslo University Hospital - Rikshospitalet, Oslo, Norway
}

Videosurgery Miniinv 2015; 10 (3): 363-367

DOI: $10.5114 /$ wiitm.2015.54315

\begin{abstract}
Introduction: Nearly 15\% of patients after laparoscopic antireflux surgery experience recurrence of symptoms or develop new gastrointestinal symptoms. Some of them require redo procedures. It can be demanding to reveal anatomical failure after previous fundoplication.

Aim: To present a method which assists in recognition of anatomical failures after Nissen fundoplication.

Material and methods: Five patients with previous laparoscopic Nissen fundoplication and severe gastrointestinal symptoms were included in this study. During the esophagogastroduodenoscopy (EGDS) two radiopaque metal clips were placed to mark the Z-line ("clips-marked Z-line" - CMZL). It was done to achieve precise visualization of the gastroesophageal junction area in the video contrast investigation. Distinctions between conclusions after the EGDS, ordinary video contrast investigation, video contrast investigation with CMZL and intraoperative findings were analyzed. Results: All patients underwent laparoscopic refundoplication with good postoperative results. There were 4 cases misdiagnosed by contrast investigation without clips and four cases misdiagnosed by EGDS. Endoscopic clipping helped to recognize correctly all anatomical failures.

Conclusions: Applying CMZL as a routine investigation before redo fundoplication can reduce frequency of misdiagnosis and help to perform redo fundoplication in appropriate patients, but it requires further studies on larger cohorts of patients.
\end{abstract}

Key words: slipped Nissen, failed fundoplication, endoscopic clipping, redo surgery, laparoscopic fundoplication.

\section{Introduction}

Laparoscopic antireflux surgery (LARS) was introduced in 1991 by Dallemagne et al. [1]. Since then, laparoscopic Nissen fundoplication has become the gold standard in patients with gastroesophageal reflux disease (GERD). The LARS procedures deliver excellent symptoms relief and provide shorter hos- pital stay and lower morbidity compared to open access.

Despite a rate of successful outcomes over $90 \%$ in many reports $[2,3]$ symptoms persist in some patients. Nearly $15 \%$ of patients report recurrence or development of new symptoms after long-term follow-up. These symptoms vary, the most common 
being dysphagia, chest and retrosternal pain, heartburn, regurgitation, vomiting, abdominal bloating, and diarrhea. In some cases symptom relief can be achieved by treatment with medications, while others require a redo operation. The number of patients who needs redo fundoplication ranges from $5 \%$ to $15 \%[2,4-6]$. The most common intraoperative findings are hiatal hernia, "slipped", disrupted, misplaced, twisted and too tight fundoplication $[7,8]$. Otherwise, the frequency of normal fundoplication wrap is up to $15 \%$ in some reports $[9,10]$.

To reveal the reason for recurrent symptoms, standard preoperative workup includes the following investigations: esophagogastroduodenoscopy (EGDS), contrast esophagography, esophageal manometry, esophageal and gastric 24-hour pH monitoring, gastric emptying studies, gastric acid analysis, computed tomography scanning, and hepatobiliary iminodiacetic acid (HIDA) scan with a gamma camera [11]. However, the results of these investigations do not always show considerable alterations, and it can be difficult to say anything about anatomical failures. Thus, there is no consensus in regard to indications for reoperation and appropriate candidates for redo LARS [11].

We have invented a diagnostic method which could help recognize anatomical failures after Nissen fundoplication. The method was proposed by one of the co-authors (Prof. B. Edwin). In the initial

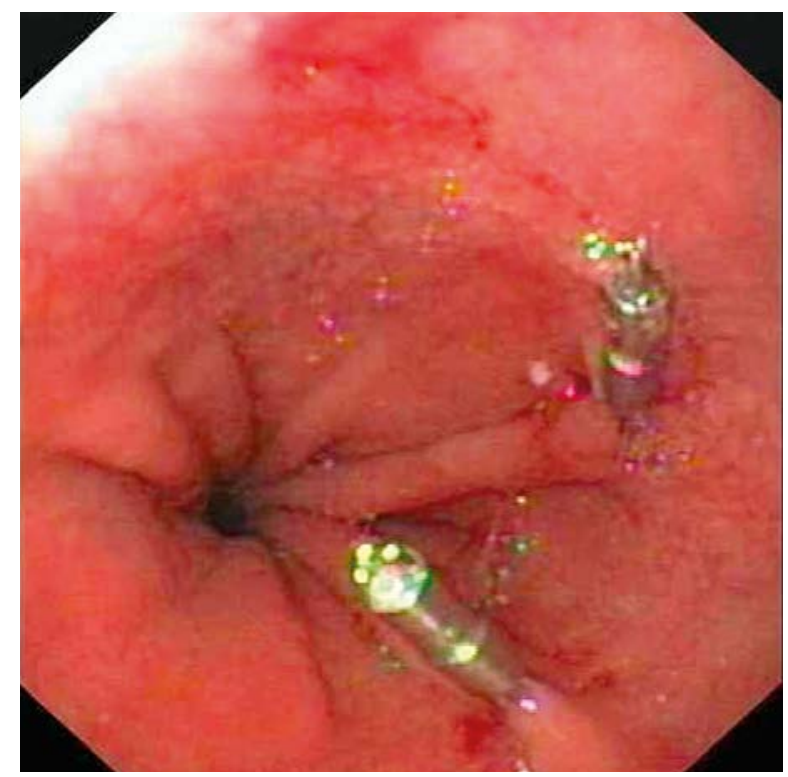

Photo 1. Two metal clips were placed at the gastroesophageal junction area - Z-line
5 patients we performed both ordinary video contrast investigation of the esophagus and video contrast investigation with "clips-marked Z-line" (CMZL) to reveal distinctive features of these methods. After the CMZL was accepted as routine study, ordinary video contrast investigation was excluded. The intention of the CMZL method is described below.

\section{Material and methods}

Five patients after laparoscopy Nissen fundoplication with severe GERD symptoms (retrosternal pain in 2 patients, regurgitation and heartburn in one, and severe dysphagia in all 5) and indications for reoperation constituted the basis of this pilot study. They underwent ordinary video contrast investigation of the esophagus, video contrast investigation with CMZL esophageal manometry, esophageal and gastric 24-hour pH monitoring and esophagogastroduodenoscopy as routine investigations.

Assessment of the fundoplication wrap with an endoscope from the inside of the stomach only reveals whether the wrap is still there or disrupted. It can be very difficult to reveal whether the wrap is slipped. During the EGDS two metal clips were placed directly at the Z-line to assess the state of the esophagus and fundoplication wrap (Photo 1). These are standard clips which are used in endoscopic procedures, e.g. to stop bleeding from vessels (Resolution, Boston Scientific, USA, QuickClip2, Olympus,

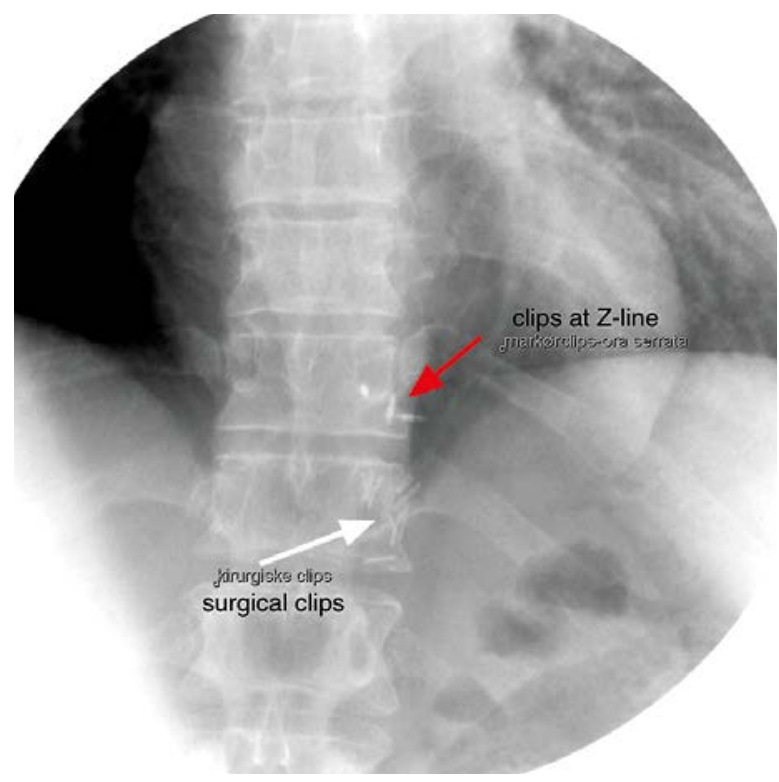

Photo 2. White arrow - clips placed during the operation; red arrow - endoscopic clips at Z-line 
Japan). Due to the long cylindrical part from radiopaque material they can be exactly visualized in $X$-ray investigations and can be easily distinguished from intraoperative clips (Photo 2). After that, patients underwent repeat video contrast study with CMZL (Photo 3). The contrast medium must not be so dense that the clip markers are obscured. We used an iodine contrast (Visipaque $320 \mathrm{mg} / \mathrm{ml}$, GE Healthcare). For better visualization of the fundoplication wrap bicarbonate can be delivered into the stomach to fill the wrap with gas. Thereby it can be better seen on $\mathrm{X}$-ray investigation (Figure 1 ).

\section{Results}

All patients underwent laparoscopic redo surgery due to severe symptoms and identified anatomical failures. Four of them underwent Nissen redo fundoplication and one underwent a Toupet procedure with good outcomes.

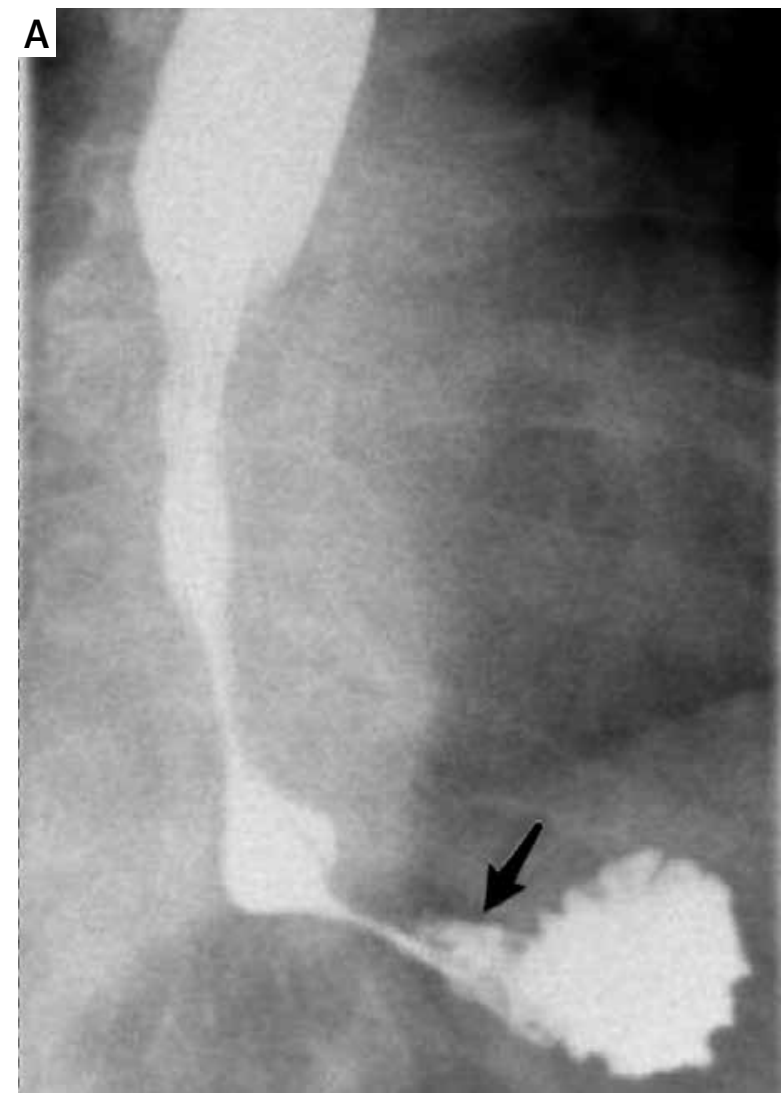

Comparison between EGDS, video contrast investigation with and without CMZL and intraoperative findings is shown in Table I. During the ordinary video contrast investigation only one of 5 cases of "slipped Nissen" was discovered. The EGDS identified "slipped Nissen" in one case as well, but in another patient. The CMZL helped to recognize all anatomical failures correctly.

\section{Discussion}

Gastroesophageal reflux is the most common esophageal motility disorder. Approximately $40 \%$ of the adult population have reflux symptoms at least once a month, $14 \%$ weekly, and $7 \%$ daily $[7,12,13]$. Of these, about $0.4 \%$ require surgical or medical treatment [14, 15]. Laparoscopic antireflux procedures has become the "gold standard" of operative treatment. Despite good short- and long-term outcomes, some patients need to undergo one or more

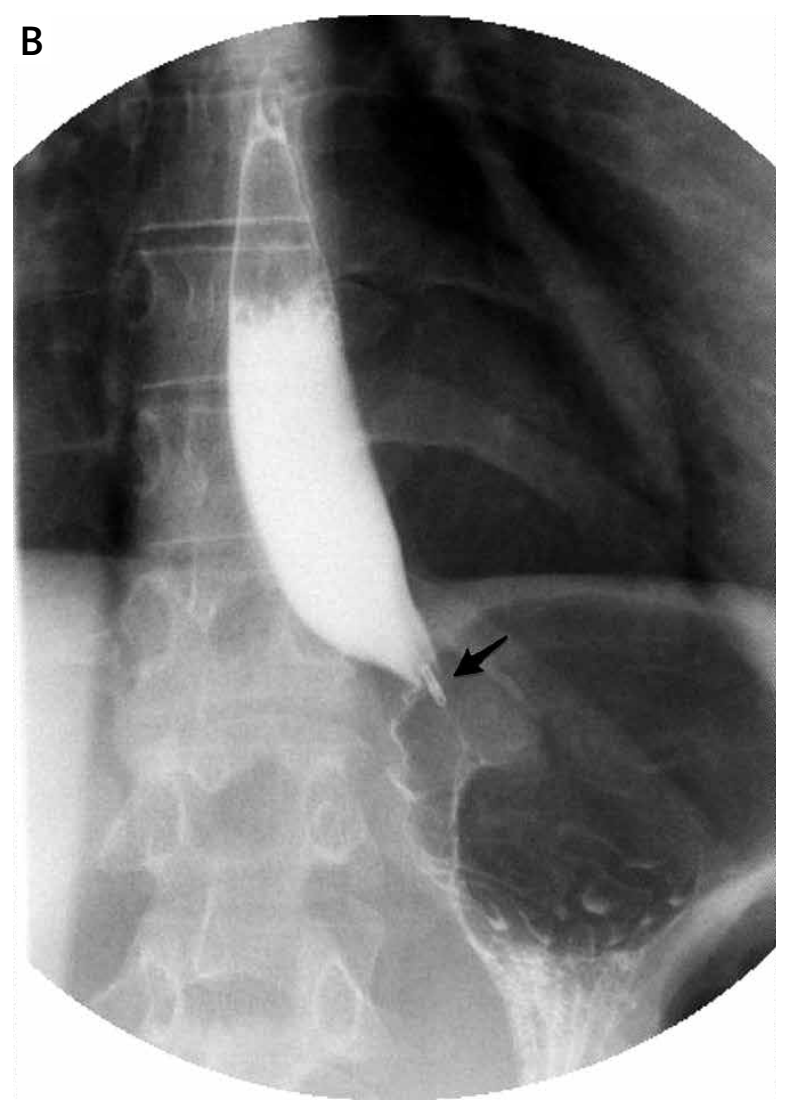

Photo 3. Video contrast investigation after transesophagus clipping. A - Patient 1: one can precisely visualize fundoplication wrap and two metal clips at Z-line. Z-line is located at the wrap area - correct fundoplication. B - Patient 2: metal clips are placed above the wrap area - fundoplication is slipped down to the stomach ("slipped Nissen"). Black arrows indicate clips 

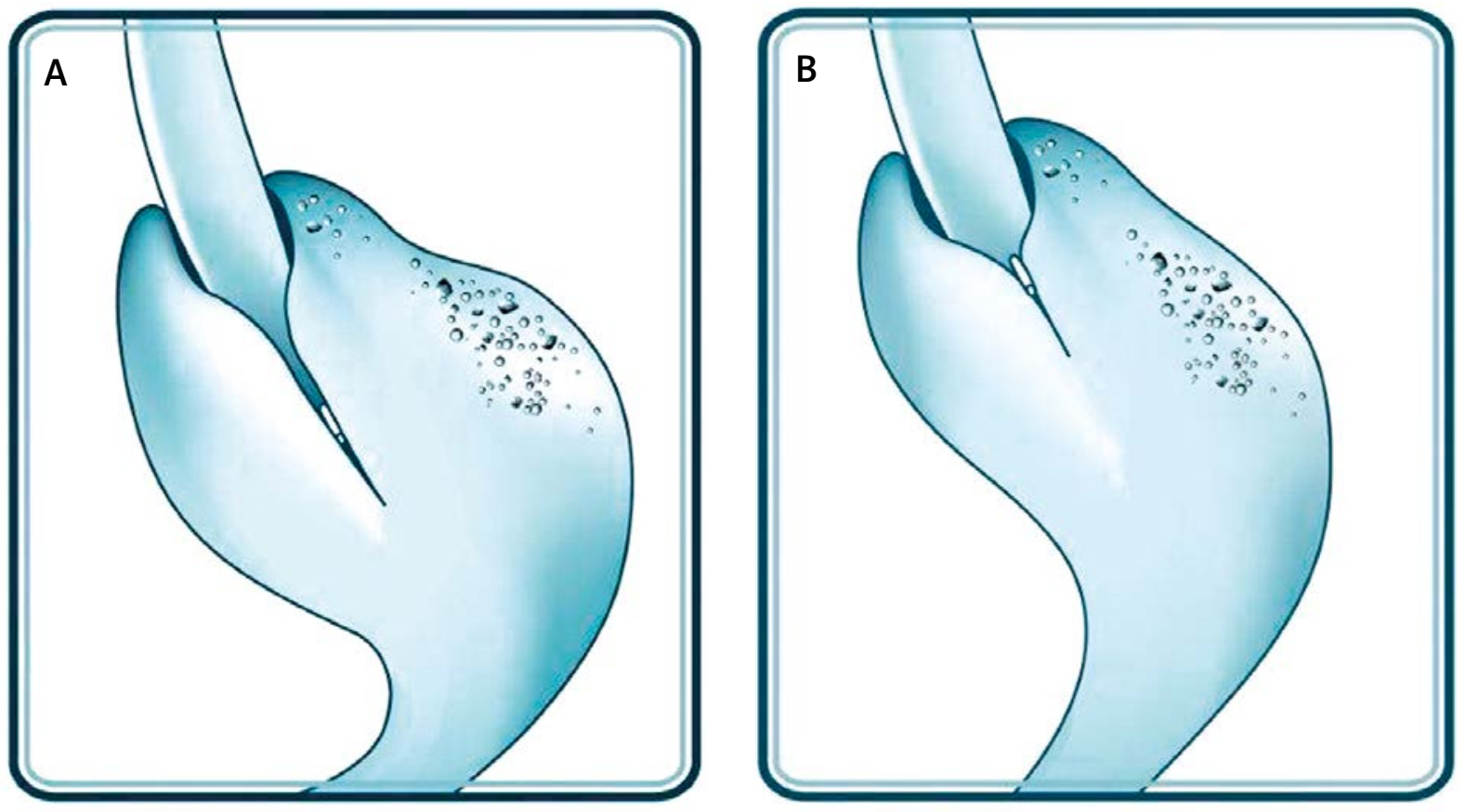

Figure 1. Scheme of position of clips in a case of normal fundoplication wrap (A) and "slipped Nissen" (B)

redo operations, and the frequency of reoperation increases with each successive redo procedure [7].

The indication to start investigations after LARS is the patient's complaints. But symptoms after fundoplication are highly various and can be induced by gastroesophageal reflux or anatomical changes after previous surgery. Analysis of intraoperative findings shows that the majority of failures are due to either disturbed or initially incorrect fundoplication [16]. However, in other cases the patient's symptoms are not associated with failed fundoplication (dysphagia caused by achalasia), or there are no changes intraoperatively, i.e. cases of misdiagnosis $[10,17]$.
In the majority of institutions worldwide, preoperative workup after failed fundoplication is the same as in cases of gastroesophageal reflux without previous surgery $[11,18,19]$. These studies can precisely investigate reflux, but in cases of anatomical failures they are not always useful. Heneghan et al. described the technique of intraoperative marking of wrap sutures by clips in 2001 [20]. This technique helps to assume the state of the wrap but not the position of the wrap regarding the esophagus. Application of the mentioned clipping method together with CMZL can help to achieve more detailed visualization of the upper

Table I. Results of EGDS, ordinary video contrast investigation, video contrast investigation with CMZL and intraoperative findings

\begin{tabular}{|c|c|c|c|c|}
\hline $\begin{array}{l}\text { No. of } \\
\text { patients }\end{array}$ & EGDS & $\begin{array}{c}\text { Ordinary video contrast } \\
\text { investigation }\end{array}$ & $\begin{array}{c}\text { Video contrast } \\
\text { investigation with } \mathrm{CMZL}\end{array}$ & Intraoperative finding \\
\hline 1 & No signs of slipped Nissen & No signs of slipped Nissen & Slipped Nissen & Slipped Nissen \\
\hline 2 & $\begin{array}{c}\text { Probably paraesophageal } \\
\text { hernia }\end{array}$ & Paraesophageal hernia & $\begin{array}{l}\text { Slipped Nissen + } \\
\text { paraesophageal hernia }\end{array}$ & $\begin{array}{l}\text { Slipped Nissen + } \\
\text { paraesophageal hernia }\end{array}$ \\
\hline 3 & No signs of slipped Nissen & Slipped Nissen & Slipped Nissen & Slipped Nissen \\
\hline 4 & Probably slipped Nissen & No signs of slipped Nissen & Slipped Nissen & Slipped Nissen \\
\hline 5 & $\begin{array}{c}\text { Probably paraesophageal } \\
\text { hernia }\end{array}$ & Paraesophageal hernia & $\begin{array}{c}\text { Slipped Nissen + } \\
\text { paraesophageal hernia }\end{array}$ & $\begin{array}{c}\text { Slipped Nissen + } \\
\text { paraesophageal hernia }\end{array}$ \\
\hline
\end{tabular}


gastrointestinal tract in the video contrast investigation.

One of the most common anatomical causes of failed fundoplication is "slipped Nissen". During the standard upper gastrointestinal investigations one can evaluate the condition of the fundoplication wrap, but it is difficult to expose the position of the wrap. The marked Z-line can be precisely visualized during a video contrast study, and it is possible to determine whether the Z-line is located above the fundoplication area (slipped Nissen), in the wrap area, or at the lower border of the wrap (acceptable result). The CMZL can also be useful to investigate herniation and short esophagus.

Applying CMZL as a routine investigation before redo fundoplication can reduce the frequency of misdiagnosis and help to perform redo fundoplication in appropriate patients, but it requires further studies on larger cohorts of patients.

\section{Acknowledgments}

We thank the graphical designer N. Maidanik for creating and providing graphical illustrations.

\section{Conflict of interest}

The authors declare no conflict of interest.

\section{Reference}

1. Dallemagne B, Weerts JM, Jehaes C, Markiewicz S, Lombard R. Laparoscopic Nissen fundoplication: preliminary report. Surg Laparosc Endosc 1991; 1: 138-43.

2. Anvari M, Allen C. Five-year comprehensive outcomes evaluation in 181 patients after laparoscopic Nissen fundoplication. J Am Coll Surg 2003; 196: 51-7.

3. Bammer T, Hinder RA, Klaus A, Klingler PJ. Five- to eight-year outcome of the first laparoscopic Nissen fundoplications. J Gastrointest Surg 2001; 5: 42-8.

4. Lafullarde T, Watson DI, Jamieson GG, Myers JC, Game PA, Devitt PG. Laparoscopic Nissen fundoplication: five-year results and beyond. Arch Surg 2001; 136: 180-4.

5. DePaula AL, Hashiba K, Bafutto M, Machado CA. Laparoscopic reoperations after failed and complicated antireflux operations. Surg Endosc 1995; 9: 681-6.

6. Hinder RA, Filipi CJ, Wetscher G, et al. Laparoscopic Nissen fundoplication is an effective treatment for gastroesophageal reflux disease. Ann Surg 1994; 220: 472-81.

7. Smith CD, McClusky DA, Rajad MA, Lederman AB, Hunter JG. When fundoplication fails: redo? Ann Surg 2005; 241: 861-9.

8. Khajanchee YS, O’Rourke R, Cassera MA, et al. Laparoscopic reintervention for failed antireflux surgery: subjective and objective outcomes in 176 consecutive patients. Arch Surg 2007 142: 785-901.
9. Dallemagne B, Arenas SM, Francart D, et al. Long-term results after laparoscopic reoperation for failed antireflux procedures. Br J Surg 2011; 98: 1581-7.

10. Bathla L, Legner A, Tsuboi K, Mittal S. Efficacy and feasibility of laparoscopic redo fundoplication. World J Surg 2011; 35: 2445-53.

11. Hinder RA, Klingler PJ, Perdikis G, Smith SL. Management of the failed antireflux operation. Surg Clin North Am 1997; 77: 1083-98.

12. Nebel OT, Fornes MF, Castell DO. Symptomatic gastroesophageal reflux: incidence and precipitating factors. Am J Dig Dis 1976; 21: 953-6.

13. Hinder RA, Libbey JS, Gorecki P, Bammer T. Antireflux surgery. Indications, preoperative evaluation, and outcome. Gastroenterol Clin North Am 1999; 28: 987-1005.

14. DeMeester TR, Van Heertum RL, Karas JR, Watson RL, Hansen JE. Preoperative evaluation with differential pulmonary function. Ann Thorac Surg 1974; 18: 61-71.

15. Papasavas PK, Yeaney WW, Landreneau RJ, et al. Reoperative laparoscopic fundoplication for the treatment of failed fundoplication. J Thorac Cardiovasc Surg 2004; 128: 509-16.

16. Stein HJ, Feussner $H$, Siewert JR. Failure of antireflux surgery: causes and management strategies. Am J Surg 1996; 171: 36-9.

17. Awais O, Luketich JD, Schuchert MJ, et al. Reoperative antireflux surgery for failed fundoplication: an analysis of outcomes in 275 patients. Ann Thorac Surg 2011; 92: 1083-9.

18. Galvani C, Fisichella PM, Gorodner MV, Perretta S, Patti MG. Symptoms are a poor indicator of reflux status after fundoplication for gastroesophageal reflux disease: role of esophageal functions tests. Arch Surg 2003; 138: 514-8.

19. Gatenby PA, Bann SD. Antireflux surgery. Minerva Chir 2009; 64: 169-81.

20. Heneghan SJ, Willis PM, Gold MS. Surgical clips to help identify anatomy after a Nissen fundoplication. Am J Surg 2002; 183 : $12-4$.

Received: 31.07.2015, accepted: 19.08.2015 